\title{
Antecedents of Job Satisfaction, Organizational Commitment and Stress in a Public Hospital: A P-E Fit Perspective.
}

\author{
Authors: \\ Corresponding author: David Giauque, Associate Professor, University of Lausanne, Institute of \\ political and international studies, david.giauque@unil.ch \\ Fabien Resenterra, PhD student, University of Lausanne, fabien.resenterra@unil.ch \\ Michaël Siggen, PhD student, University of Lausanne, michael.siggen@unil.ch
}

\section{Acknowledgement:}

This article is part of a broader research project financed by the Swiss National Science Foundation (project no. 13DPD6_134764/1).

\begin{abstract}
:
This article tests different P-E fit dimensions in order to assess their impact on three work outcomes: job satisfaction; organizational commitment; and stress perception. Findings shows that P-E fit dimensions have differentiated effects on its dependent variables. This study contributes to several important academic discussions. The first concerns the model tested, which contains several P-E fit dimensions. The second scientific contribution is to consider P-E fit dimensions as antecedents of three job outcomes. The third contribution concerns the development and testing of a new P-E fit dimension called "person-reforms" fit.
\end{abstract}

Keywords: P-E fit; person-reforms fit; job satisfaction; organizational commitment; stress perception

\section{Article classification:}

Research paper

This article is published in Public Organization Review. This current paper corresponds to a final draft post-refereeing version. The original publication is available at www.springerlink.com. 


\section{Introduction}

Swiss public hospitals are currently confronting multiple challenges and reforms, facing numerous changes with respect to their funding procedures, quality assessment, and management and steering. In this context of profound management and steering reform, middle-range managers of public hospitals are under a new kind of pressure. They must translate and implement these reforms whilst managing frontline employees at the same time. In short, they are key actors in the implementation process of the hospital reforms while also in charge of leading teams in their organization. Job demands have therefore greatly increased for this category of employee. In this new climate of policies and managerial pressure, it is of great academic interest to assess the work attitudes of middle-range employees. More specifically, the aim of this study is to assess whether Person-Environment fit (P-E fit) might be considered as an antecedent of work outcomes (job satisfaction, organizational commitment, and stress) among these middle-range employees. In their extended meta-analysis, Kristof-Brown et al. define the concept of P-E fit as "the compatibility between an individual and work environment that occurs when their characteristics are well matched" (Kristof-Brown et al. 2005: 281). And, "In a classic work, Vroom (1964) pointed out that there should be a fit between a person's characteristics and attitudes on the one hand and the workplace on the other. Lack of fit between these aspects can have negative effects. This point can be seen in the literature when the need is stressed for congruence between workers' motives and the incentives given by the organization..." (Steijn 2008: 14).

There have been numerous studies showing that P-E fit matters in terms of work outcomes, such as job satisfaction, organizational commitment, work motivation and intention to leave (Kristof-Brown et al. 2005). Much of the existing P-E fit research treats fit as a mediator between other concepts of interest. Consider, for instance, recent Public Service Motivation (PSM) research (Bright 2008; Steijn 2008; Wright and Pandey 2008), which clearly holds that the benefits of PSM (e.g., on performance, turnover) are contingent on whether or not a person fits with their organization. Fit has become, in other words, the lynchpin between concepts. While salient points of research have been uncovered in these previous studies, their tendency to view fits as mediators is, however, debatable. In most research, fits are investigated by questioning respondents on their perception regarding their fit with their organization, their colleagues, their job, and their general vocation. Therefore, fits' perceptions might also be considered as a subjective reality that might directly impact on work outcomes such as job satisfaction (JS), organizational commitment (OC), or even stress perception. Perceptions of fit are therefore likely to impact individuals' attitudes towards their jobs: a feeling of fit will have a positive outcome while a feeling of misfit will have a negative one. This logic has been widely studied and the consequences of individuals' fit at work are now well established (Kristof-Brown et al. 2005). Why, then, does the field need another article on this topic? First, because the literature on P-E fit has been developed only in the last five years. Indeed, most of the time, P-E fit is studied according to two main dimensions: Person-Organization fit and Person-Job fit. Recent literature suggests that P-E fit is in fact a more complex concept composed of multiple dimensions (Edwards and Billsberry 2010; Vogel and Feldman 2009; Kristof-Brown et al. 2005). The P-E fit concept has thus been extensively tested and expanded to incorporate these new dimensions. Drawing upon the current literature, this study aims to determine whether JS, OC, and stress might be explained by different dimensions of P-E fit. Furthermore, it is our goal to find out whether these latter variables might be explained by the same fit antecedents. In this regard, this article will test a model in which Person-Organization fit, Person-Job fit, Person-Group fit, Person-Vocation fit, and Person-Reforms fit are considered as hypothetical antecedents of JS, OC, and stress among a population of middle-range employees in a Swiss public hospital. This perspective is particularly useful for elucidating the evolution of the context of Swiss public hospitals, which are currently being confronted with many reforms aiming to increase their productivity and financial accountability. In such a context, perceptions of fit between individuals' characteristics and the characteristics of their work environment are crucial. Many studies have demonstrated that in terms of work outcomes, values do matter. Individuals carry values, or special needs that may or may not be supplied by their work environment. Their direct perception of fit according to their organization, job, vocation, group to which they belong, and reforms undertaken might therefore affect their satisfaction, commitment, and well-being as well. Furthermore, studies have also found that stress, job satisfaction and organizational commitment are important work 
outcome variables in the context of organizational reforms (Yousef 2000; Noblet and Rodwell 2009). Thus, this paper will take into account recent P-E fit research and test the direct relationships of several dimensions of this concept rather than using P-E fit as a mediator.

This article contributes to several important academic discussions and offers an innovation to previous research. The first discussion concerns the model tested, which contains several P-E fit dimensions. Empirical tests of such P-E fit dimensions have been developed in previous studies but few of them actually test them simultaneously. One of our research objectives, therefore, is to assess the individual contribution of several P-E fit dimensions to the explanation of three work outcomes (JS, OC, and stress). The second scientific contribution is our consideration of P-E fit dimensions as antecedents of three job outcomes in the specific population of a Swiss public hospital: middle-range managers. In our opinion, it is of great interest to investigate how feelings of fit/misfit among middle-range managers might contribute to explaining their level of perceived stress, job satisfaction, and organizational commitment. Job stress is now a major concern in Swiss public bodies, as it is elsewhere. But currently, few studies address the link between occupational ill-being and P-E fit dimensions. The third scientific contribution, which also constitutes our study's innovation, is to include a new dimension in the P-E fit concept. In this paper, we develop and empirically test a new PE fit dimension called P-R fit (person-reforms fit) to see whether this variable might explain work outcomes (JS, OC, stress) among our studied population (managers in a public hospital). Indeed, in a context of public management reforms, it is of great interest to know if individuals' perception of fit or misfit between their organization's goals and values and the ones embedded in the reforms that have taken place in the last few years might explain some of their work attitudes and behaviors.

In response to the aforementioned issues, this article will be developed as follows. The first chapter will be dedicated to the presentation of the main dependent variables (job satisfaction, organizational commitment, and stress perception). The second will present the P-E fit concept, its dimensions, and our hypotheses. The third will concern the data and methods used to test our explanatory model. Then we will discuss the main results of our empirical analyses and, finally, we will propose some concluding remarks and comments with respect to future research possibilities, and we will also consider some of the limitations of this study.

\section{Context of the study: reforms in Swiss public hospitals}

This present study has been developed in a specific context. Swiss public hospitals are currently confronted with many reforms inspired by New Public Management principles and practices. We will quickly define several important recent changes that greatly affect public hospital management and steering. First of all, the hospital financial system was reformed and approved in 2007 by the Swiss Parliament. The general principles of this important reform aim to clarify the financial accountability of the different actors embedded in the Swiss hospital system. This new financial system aims also to invite these different actors (especially public hospitals) to better control their expenses by implementing new managerial practices as well as finance the services that are really being delivered. Swiss public hospitals are therefore now obliged to finance their activities according to a new system that attributes a precise amount for every service delivered. In other words, Swiss public hospitals have to now deal with Diagnosis Related Groups (DRG) with the result that every service is related to a precise price or rate. These rates are defined according to the average cost of each service delivered by Swiss public hospitals. The main objective of this new financial system is to harmonize the rates of the different services supplied in public hospitals throughout the country so as to bring more transparency and accountability to overall hospital costs and to facilitate benchmarking between the different hospitals.

This particular reform, among others, has had some consequences on public hospitals. First of all, they are now in direct competition with one another and hospitals that are unable to offer services according to the defined rates will subject to a deficit. The new financial system therefore incentivizes managerial actions within hospitals. Also adding to this picture is the fact that public hospitals are currently managed through contracts. This means that public hospitals, which are steered by the cantonal level of governance (Switzerland counts 26 cantons), are financed by the federal and cantonal 
level but their missions are stipulated in a contract they have to negotiate with their political supervision authority (at the cantonal level). These contracts prescribe the services that hospitals have to supply and they include several indicators, which serve to assess whether the hospitals have concretely supplied the services for which they are being paid. This system leads to some important internal managerial changes such as the development of cost accounting. In other words, the reform of the financial system of public hospitals leads to important organizational changes, as well as the development of new managerial practices within them.

In short, the specific context of Swiss public hospitals may be characterized by profound accountability, steering, and managerial transformations. It is thus of great interest to investigate perceptions of fit amongst public hospitals' middle-range employees in such a context, and to test whether fit perceptions might explain work outcomes, such as JS, OC, and stress.

\section{Theoretical framework: P-E fit}

Person-Environment fit (P-E fit) is now a well-known concept that has been established and documented in management literature (O'Reilly et al. 1991; Kristof 1996). Numerous studies have found empirical evidence that P-E fit is positively associated with job attitudes (e.g. job satisfaction, subjective career success, and intention to remain) and with job behaviors (citizenship behavior) (Kristof-Brown et al. 2005; Vogel and Feldman 2009; Da Silva et al. 2010; Christensen and Wright 2011). With that said, the P-E fit concept has been recently tested and expanded. Edwards and Billsberry (2010), for example, explored the multidimensionality of employees' fit by testing an alternative model of multidimensional fit that assumes no overarching sense of fit (Edwards and Billsberry 2010). According to different statistical tests (Confirmatory Factor Analyses), they found that different dimensions of P-E fit individually influence work outcomes (commitment, job satisfaction, and intention to leave). They conclude that "these results suggest something quite important, namely that employees who have been employed by their organizations for a year or more do not have an overarching sense of fit. Instead, employees make fit assessments to various aspects of the organizational environment such as their jobs, the people they work with, and the overall organization. These do not appear to coalesce into an overarching sense of fit before influencing commitment, intention to leave, and job satisfaction, and instead operate separately on the outcomes" (Edwards and Billsberry 2010: 488).

Drawing upon such empirical findings, we will consider person-organization fit (P-O fit), person-job fit (P-J fit), person-group fit (P-G fit), person-vocation fit (P-V fit), and person-reforms fit (P-R fit) as predictors of three work outcomes, which will be presented later.

As stated earlier in this article, P-E fit is a broad concept which includes several dimensions. Moreover, empirical evidence shows that the underlying dimensions of P-E fit have differentiated impacts on job outcomes (Edwards and Billsberry 2010). According to these empirical findings, we depart from the theoretical assumption that dimensions of P-E fit that will be included in this study must be analyzed separately in order to assess their respective contribution on work outcomes. In the following section, we will explain the different dimensions we will include in this study and formulate our hypotheses.

$\boldsymbol{P}$-O fit. Person-organization fit is a well-known concept and has been studied widely in previous research. This dimension may be defined as the congruence between individuals and their organization in terms of values and goals (Kristof 1996; Kristof-Brown et al. 2005). "The logic here is that individuals prefer to work in environments that reinforce their self-concepts. Thus, since values are a fundamental part of how individuals view situations and judge acceptable behavior, achieving value congruence is fundamental to successful adaptation to workplace" (Vogel and Feldman 2009: 69). Furthermore, researchers have also found consistent positive relationships between P-O fit and job outcomes such as job satisfaction, intention to leave, career success, in-role performance, and citizenship behaviors (Bretz and Judge 1994; Bright 2007; Da Silva et al. 2010; Caldwell 2011). 
$\boldsymbol{P}-\boldsymbol{J}$ fit. Person-job fit refers mainly to individuals' congruence with the job of which they are in charge: "PJ fit generally relates to the complementary nature of demands or benefits of one's job in relationship with the abilities or needs of the individual employee. PJ fit has been found to relate positively with job satisfaction and performance and negatively with job stress" (Caldwell 2011: 403). It is indeed very likely that an individual's goals and values might be aligned with those of his organization, but at the same time, there might be an incompatibility between the main missions and goals of his job and his abilities or job preferences. The contrary might also be true. For instance, in public hospitals, managers are also recruited amongst doctors. While their new role might be in line with their organizational goals, they might not feel comfortable with their supervision missions, which are specific to their job. Therefore, it is likely that these two dimensions might have differentiated impacts on job attitudes and behaviors.

$\boldsymbol{P}$ - $\boldsymbol{G}$ fit. Person-group fit is another important dimension of P-E fit. It deals with the congruence between employees and the group of which they are a part: "Person-group fit exists when there is interpersonal congruence between the individual and other members of the immediate work group. The construct has been operationalized in several different ways; most often, individuals are compared to their coworkers in terms of goals, values, or personality traits" (Vogel and Feldman 2009: 70). When individuals achieve fit with their colleagues, it is very likely that this positive job climate might also influence job attitudes and job behaviors. Feelings of congruence with team members might also be linked negatively with feelings of job stress, since previous research investigating job stress has consistently demonstrated the negative relationship between colleagues' support and job stress (Karasek and Theorell 1990; Lallement et al. 2011; Lee and Akhtar 2011; Vézina 1999). Thus, previous empirical research has found that positive relationships between $P-G$ fit and in-role and extra-role performance (Kristof-Brown et al. 2005).

$\boldsymbol{P}-\boldsymbol{V}$ fit. Person-vocation fit mainly concerns the match/mismatch between individuals' interests and abilities and the specificities of their vocation. Since P-J fit and P-V fit are considered to be closely related concepts, it is useful to highlight the differences between them: "Although somewhat related, $\mathrm{P}-\mathrm{V}$ fit differs in significant ways from P-J fit. For some workers, the concepts of vocation and job may have considerable overlap; however, many situations exist where this is not the case. P-V fit refers to the congruence of skills and needs at the level of the occupation. In contrast, P-J fit refers to the congruence present in a specific position. Consequently, it is possible for individuals to achieve PV fit but not P-J fit" (Vogel and Feldman 2009: 70). For example, a doctor or a nurse might have the skills and abilities to take care of patients and, therefore, to feel professionally satisfied (high P-V fit), but at the same time, they might be a poor fit for a particular job assignment (low P-J fit) because they lack the necessary skills or because they might not share the missions or goals of their job position. Previous research has shown a positive association between P-V fit and job satisfaction and in-role performance (Spokane 1985; Tranberg et al. 1993).

$\boldsymbol{P}-\boldsymbol{R}$ fit. Despite the fact that this particular dimension has not yet been studied in the literature with respect to P-E fit, we believe it is worth studying in the specific context of our study. Because Swiss public hospitals are confronting significant public policies' reforms, which are mainly driven by the federal government, it is of great interest to question the congruence between individuals' perception of their organization's mission and those embedded in the reforms that have taken place in the last few years. Middle-range employees of Swiss public hospitals have not been consulted in the definition or implementation of health sector reforms in Switzerland. Some of them might believe that the goals, values, and orientations of these reforms are incompatible with the goals, values, and orientations of their job or vocation. In this case, it is very likely that P-R fit might influence the level of job attitudes and job behaviors of Swiss public hospitals' middle-range employees.

\section{Job satisfaction, organizational commitment, and stress}

Before presenting our different hypotheses and empirical expectations with respect to our three dependent variables, we will explain why we expect that our independent variables (P-E fit dimensions) will be associated with the work outcomes selected in this study. Many theoretical backgrounds could be invoked to explain these expected relationships, but in the interest of time, we 
will briefly present only a few of them. Firstly, sociological literature has demonstrated that "professional organizations" (hospitals typically fall under this category) are specific (Meyer and Rowan 1991; Evetts 2009; Kitchener 2000). Indeed, professionals benefit from a socialization process through their professional training, for instance, which contributes to shaping their vision with respect to their professional values, missions, and goals. In return, this "vision" contributes to the elaboration of specific professional expectations. When entering into an organization, these professionals expect, therefore, to work in a particular work climate, which fits with their professional vision. Thus, professionals will compare their work environment with their professional expectations (their values, a specific vision of missions, tasks, and so on), which will result in either a fit or misfit perception. This fit or misfit perception could be related to different dimensions: organization; job; group; vocation; reforms undertaken in their work environment. Therefore, both the socialization process and values matter in organizations. When we consider P-E fit in the context of social exchange theory (Eisenberger et al. 1990), we depart from the idea that employees are prone to make efforts for their organization if they feel that they benefit from a supportive work environment: "On this basis, where employees perceive that organizations value and deal equitably with them, they will reciprocate these good deeds with positive work attitudes and behaviors" (Gould-Williams and Davies 2005: 4). Social exchange theory also deals with "a fit perspective," which considers that employees who feel that their organization offers good work conditions will be more willing to reciprocate this organizational support by making a greater effort at work and exhibiting a higher level of satisfaction and organizational commitment. Once again, this social exchange is related to multiple organizational dimensions and is grounded on fit assessment regarding the work environment. Understanding P-E fit in the context of sociological theory and social exchange theory demonstrates why we expect that our independent variables (P-E fit dimensions) will be related to our dependent variables, which will be presented in more detail now.

Job satisfaction (JS) focuses principally on individuals' response to the experience of their job. This is probably the most widely investigated job attitude. According to the literature, job satisfaction may be defined as "a positive emotional state resulting from employees' appraisal of their jobs" (Taylor 2007: 939). As noted by social scientists, work satisfaction is a work outcome that focuses on employees' responses to their job experiences (Mowday et al. 1982).

As stated by Taylor, "most efforts to explain job satisfaction are based on the person-environment fit paradigm. Put simply, workers with higher satisfaction levels are those who have developed a better fit psychologically between their personal needs or values and the characteristics of their jobs. (...) Employees who are satisfied with their jobs will perceive that their job fulfils, or allows for the fulfillment of, values that are important to them" (2007: 939).

Moreover, job satisfaction is mainly defined as a positive emotional state resulting from employees' appraisal of their jobs (Agho et al. 1993; Locke 1976; Taylor 2007).

Although the relevance of the job satisfaction concept is currently under scrutiny and is considered by some as "a throw-away variable" (Staw 1984), other critics point out that the job satisfaction construct has received little attention even though its use has been widely developed by both practitioners and academics (Büssing 1992). Other authors are also critical and advise caution when observing the consistently high proportion of satisfied employees (Szilagyi and Wallace 1983; Weaver 1980). In any case, the concept of job satisfaction has been defined in many ways. However, the most-used definition of job satisfaction in organizational research is that of Locke (1976), who described job satisfaction as a "pleasurable or positive emotional state resulting from the appraisal of one's job or job experiences" (p. 1304). Of course, measurement of job satisfaction is still a controversial issue and there are many different ways to assess employees' job satisfaction, but we will not be exploring this specific issue in the present article.

Several theories regarding antecedents of job satisfaction have been proposed. These theories can be loosely classified into one of three categories: 
1. Situational theories, which hypothesize that job satisfaction results from the nature of one's job or other aspects of the environment.

2. Dispositional approaches, which assume that job satisfaction is rooted in the personological makeup of the individual.

3. Interactive theories, which propose that job satisfaction results from the interplay of situational and personlological factors" (Judge and Klinger 2007: 398-399).

Regarding the background of the situational theories, which will more particularly developed in this article, authors have shown that jobs containing intrinsically motivating characteristics will contribute to higher levels of job satisfaction (Hackman and Oldham 1976). Five job characteristics may define an intrinsically motivating job: (1) task identity or the degree to which an employee can see his work through from $\mathrm{A}$ to $\mathrm{Z}$ or from the beginning to end; (2) task significance or the degree to which an individual considers his work as important and significant; (3) skill variety or the extent to which an employee may use different skills in his day to day work; (4) autonomy or the degree to which an employee may benefit from discretion and control over his job; and (5) feedback or the degree to which an employee may benefit from feedback regarding the way he performs his job. "According to the theory, jobs that are enriched to provide these core characteristics are likely to be more satisfying and motivating than jobs that do not provide these characteristics" (Judge and Klinger 2007: 399). Numerous studies have shown the accuracy of such a theory, stressing that when employees are asked to assess different facets of their job (supervision, pay, promotion opportunities, coworkers, and so forth), the job itself is generally considered as the most important job facet (Judge and Church 2000). Similar results may also be found in public management literature. Thus, drawing on secondary data covering more than 14,000 Dutch public employees, Steijn found that the impact of individual characteristics on job satisfaction is very small, whereas job and organizational characteristics are more important antecedents, more specifically the instrinsic aspects of the work situation (Steijn 2004). In the same vein, Noblet and Rodwell found that Australian police officers are more likely to be satisfied if they benefit from more decision-making latitude, independence in their job, and support from supervisors and co-workers (Noblet and Rodwell 2009). Job characteristics (work autonomy and good working relationship with supervisors and co-workers) are also identified as the most important job satisfaction antecedents in other comparative studies including public servants from seven countries (Taylor and Westover 2011). The above results show that job satisfaction is more specifically related to job characteristics, job content, and social relationship (support from supervisors and co-workers). Therefore, we expect that P-J, P-V and P-G fits will be related to job satisfaction.

Hla: $P-O$ fit won't be significantly related to job satisfaction

$H 1 b$ : P-J fit will be significantly and positively related to job satisfaction

H1c: P-V fit will be significantly and positively related to job satisfaction

H1d: P-G fit will be significantly and positively related to job satisfaction

Hle: P-R fit won't be significantly related to job satisfaction

Organizational commitment is a concept that has been the subject of numerous studies. It does not necessarily conform to a universal definition or means of measurement (Meyer and Herscovitch 2001). Furthermore, other concepts that are similar or connected may arise to cloud the understanding of organizational commitment. Certain authors therefore warn against reducing commitment to terms such as 'motivation' or 'attitudes' (Brown 1996; Scholl 1981), suggesting rather that commitment influences the behavior of individuals in a manner that is independent of their personal motivation and interests. As a result of this, organizational commitment implies extreme professional loyalty, as well as a depth of identification (Steinhaus and Perry 1996). Moreover, as we are reminded by other literature, the concept of organizational commitment should be extremely reliable for measuring human behavior in organized groups; more so, in any case, than other theoretical constructs such as job satisfaction or job involvement (Jae Moon 2000). Crewson (1997) furthermore presents a precise, clear definition of organizational commitment, which he qualifies as being an individual identification with and involvement in an organization. He emphasizes that it is made up of three distinct factors : a strong belief in and acceptance of the organization's values and aims; a significant willingness to work hard for one's organization ; and a desire to remain a member of it. The other great advantage of the concept, as shown by numerous research projects, is that it has a strong correlation with better performance at work (Larson and Fukami 1984; Van Maanen 1975) as well as a significant negative 
correlation with costly behavior such as absenteeism, delays and even turnover (Koch and Steers 1976). Meyer and Allen have developed a model of commitment with three components, which is widely known today (Meyer and Allen 1991, 1997) and which forms the basis of a large number of empirical studies. Meyer and Allen consider the three components of their commitment model as 'mind sets', which may induce different attitudes and behavior towards the organization. Thus, affective commitment represents an emotional attachment to the organization, continuance commitment refers back to the costs that may be incurred by the employee as a result of a decision to leave the organization, and normative commitment represents the feelings of obligation experienced by an individual towards the organization (Meyer and Herscovitch 2001). The behavioral consequences of these three mind sets are identical: a continuation of the employment relationship.

Turning now to the literature on the antecedents of $\mathrm{OC}$, several interesting findings may be pointed out. Camilleri, for instance, developed a model of analyis in which he included five categories of OC antecedents (personal attributes, role states, employee perception of the organization, employee-leader relations, and, finally, job characteristics) (Camilleri 2006). He found that the employee perception of organization antecedent is the best predictor of OC. In another study, Giauque et al. pointed out that perception of organizational support, procedural justice, and organizational reputation have strong correlations to OC (Giauque et al. 2010). Procedural justice and organizational support are also found as predictors of OC in other studies (Tremblay et al. 2010). In the same vein, Meyer and his colleagues conducted a meta-analysis regarding OC. They included many antecedents' variables in order to explain OC and have concluded that a supportive work environment has the strongest influence among possible antecedents of OC (Meyer et al. 2002). Therefore, internal processes and structures seem to be relevant for enhancing OC. Stazyk and his colleagues has developed another model to include institutional variables to explain OC. They depart from the idea that $\mathrm{OC}$ in public organizations are also related to external control from politicians and political principles: "(...) We include bureaucratic red tape and organizational goal ambiguity in our model, arguing both are consequences of external control and antecedents in a causal chain leading to organizational commitment" (Stazyk et al. 2011: 607). They found that public organizations' environment impacts OC because external control of public organizations increases organizational goal ambiguity and red tape, which contribute to role ambiguity, with the latter variable being negatively related to OC. In short, there is a body of evidence to suggest that $\mathrm{OC}$ antecedents are principally organizational variables, such as perception of organization, procedural justice, organizational support, and organizational reputation. A more recent study shows that environmental variables, such as external control, goal ambiguity, and red tape may also be considered as predictors of OC. This latter result demonstrates that fit according to what happened in the environment of the organization, such as global reforms or changes in terms of public policies, are worth studying in order to explain OC. These above results lead us to determine five more hypotheses with respect to OC.

H2a: $P-O$ fit will be significantly and positively related to $O C$.

$H 2 b$ : $P-J$ fit won't be related to $O C$.

$H 2 c$ : $P-V$ fit won't be related to $O C$.

H2d: $P-G$ fit won't be related to $O C$.

H2e: $P$-R fit will be significantly and positively related to $O C$.

Stress. The two principal and most common theoretical models developed to measure and explain the degree of stress or unhappiness amongst employees were identified three decades ago by Karasek (1979) and Siegrist et al. (1986). The first model includes two major dimensions of work organization: on the one hand, the workload of the employee characterized as a psychological burden attached to time pressures (demand), and on the other, the ability and flexibility that employees have over their professional activities (control) (Bakker et al. 2008; Karasek 1979). This model predicts a heavy psychological burden associated with high levels of perceived stress and the possibility of a greater prevalence of psychological distress. When prolonged and sustained, psychological distress is a source of various detrimental mental disorders. However, demanding work requirements are less harmful when employees benefit from a substantial degree of job flexibility, have the opportunity to participate in defining the rules relating to their job, or can make extensive use of their vocational and social skills. This first approach, also called the "Job Demands Control Model", has subsequently been 
enriched by a third dimension: social support (Johnson 1986; Johnson and Hall 1988). This additional dimension comprises three facets: support of management (director, supervisor); support of colleagues (peer support); and support of family and friends (non-professional support). Social support reduces the negative impact of a heavy workload.

Siegrist (Siegrist 1996) has, meanwhile, developed a second model: "Effort-Reward Imbalance at work". This model identifies a relationship, characterized by a reciprocal modulation, between the psychological and social recognitions that occur within an organization. This model presumes that employees are more likely to be confronted with stress if their efforts are not sufficiently rewarded or recognized either subjectively or objectively by their organization. Such an expression of organizational gratitude can be given by means of provisioning material rewards, such as a pay rise or career advancement, or by means of intangible rewards, such as promotion, training, and so on. In other words, a job that is too demanding is harmful when tangible and intangible recognition for work is not commensurate with the efforts made by employees (Siegrist 1996; Siegrist et al. 1990; Siegrist et al. 1986). These two models have been used in numerous quantitative empirical studies. They have shown that time pressure, workload, and lack of resources, social support, and tangible or intangible rewards are indeed major contributory factors for perceived job stress.

Another model, the JD-R model (Bakker and Demerouti 2007; Demerouti et al. 2001) has been tested in various work settings and has been found to be empirically sound (for a comprehensive presentation of its empirical use, see Bakker and Demerouti 2007). This model is based on previous theoretical and empirical developments which have shown that stress or work tension are the results of two interrelated phenomena: the organizational and job constraints with which employees are confronted and the degree of job control that employees may utilize to face their job requirements and work challenges. These theoretical and empirical developments can be considered as a consensual framework in the scientific community specialized in the study of stress. The vast majority of research undertaken in the past few years to explain stress and burnout have been developed around these theoretical arguments (Maslach et al. 1996; Demerouti et al. 2001; Schaufeli and Enzmann 1998; Schaufeli and Bakker 2004).

The JD-R model points to a broad variety of work aspects that affect employees' wellbeing. These job characteristics can be classified in two higher-order opposing categories: job demands and job resources. On the one hand, "job demands are defined as those aspects of the work context that tax employees' personal capacities and are, therefore, associated with certain psychological and/or physiological costs" (Van den Broeck et al. 2008). Work overload, organizational constraints, emotional demands, work-home conflict, and interpersonal conflict are job demand factors proven to be positively related to stress if they exceed employees' adaptive capacities (Schaufeli and Bakker 2004; Bakker et al. 2008; Noblet et al. 2006; Richardsen et al. 1992; Van den Broeck et al. 2008). On the other hand, "the category of job resources is defined as those physical, psychological, social, or organizational aspects of the work context that (1) can reduce the health impairing impact of job demands, (2) are functional in achieving work goals, and (3) stimulate personal growth, development, and learning" (Van den Broeck et al. 2008). Opportunities for skill utilization, supervisor support, colleague support, financial rewards, career opportunities, team cohesion, harmony, autonomy, and coaching are the main aspects identified as resources that enable employees to work in a healthy atmosphere (Bakker and Demerouti 2007; Demerouti et al. 2001; Johnson and Hall 1988; Schaufeli and Bakker 2004; Siegrist 1996; Van den Broeck et al. 2008). Most of the time, job resources dimensions commonly considered in empirical research are mainly related to social (supervisor or colleague support and cohesion) or work characteristics (autonomy, career opportunities, tangible or intangible rewards, and skill utilization). According to the results presented above, we have developed five more hypotheses in relationship with stress.

H3a: P-O fit won't be related to stress.

H3b: P-J fit will be significantly and negatively related to stress.

H3c: P-V fit will be significantly and negatively related to stress.

$H 3 d$ : $P-G$ fit will be significantly and negatively related to stress.

H3e: P-R fit won't be related to stress. 


\section{Data and measurement}

\subsection{Sample}

To empirically test the previous hypotheses, this study used a sample from a large public hospital in the French-speaking region of Switzerland. In order to optimize the response rate in our survey, we first contacted the Human Resources Department of the hospital, whereupon the executive members of the hospital gave their official approval of our study. The questionnaire was developed in partnership with the leaders of the HR Department. After a test phase, an Internet link leading to the questionnaire was sent to all middle-range employees by e-mail with a cover letter signed by the hospital officials. The employees were invited to fill out the electronic questionnaire within a month (mid-January to mid-February of 2012). A reminder was sent at the end of January to check that all employees had had the opportunity to complete it. To ensure complete privacy, answers were directly saved on a server belonging to our research team. No hospital employees had access to this data and employees were completely and transparently informed about the procedure. The announcement of these precautions had two purposes: to increase the participation rate and to function as a baseline requirement to prevent common method bias (Podsakoff et al. 2003).

830 middle-range employees were contacted by e-mail and a total of 492 employee surveys were returned (response rate, 59.3\%). Although the response rate is rather high, it is in fact comparable to numerous other studies on work outcomes. Due to their missing data, we decided to delete incomplete questionnaires, bringing the final number of employee surveys in this study to 407. It should also be noted that we focused our attention on a single public hospital, which can be considered as a limitation. In the future, it would be instructive to extend our research questions to other important hospitals in Switzerland in order to compare the empirical results.

The table 1 below contains some indications with respect to the population of this present study.

Table 1: characteristics of the sample

\begin{tabular}{rll}
\hline Age: & First category: From 18 to 29 & $0.4 \%$ \\
& Second category: 30-39 & $14 \%$ \\
& Third category: 40-49 & $37.6 \%$ \\
& Fourth category: 50-59 & $39.6 \%$ \\
& Fifth category: 60 and more & $8.4 \%$ \\
\hline Gender: & Female: & $44.3 \%$ \\
& Male: & $55.7 \%$ \\
\hline Educational level ${ }^{1}:$ & Apprenticeship: & $16.1 \%$ \\
& High school: & $29.1 \%$ \\
& Specialized professional education: & $32.7 \%$ \\
& University: & $54.7 \%$ \\
\hline Type of middle-range employees: & Nursing manager: & $35.2 \%$ \\
(function) & Medical manager: & $27.5 \%$ \\
& Administrative/financial manager: & $11.9 \%$ \\
& Technical manager: & $12.6 \%$ \\
& Other: & $12.8 \%$
\end{tabular}

\subsection{Measures}

The survey items used to construct the study variables can be found in the appendix. The independent variables in this study are P-O fit, P-J fit, P-G fit, P-V fit, P-R fit. With respect to these six "fit" dimensions, it is important to note that the scales developed to measure them rely on a "complementary fit" conceptualization. According to Muchinsky \& Monahan, for complementary fit, "the basis for a good fit is the mutually offsetting pattern of relevant characteristics between the person and the environment" (Muchinsky and Monahan 1987). Furthermore, we have opted to deploy a

\footnotetext{
${ }^{1}$ As you can probably observe the total for this variable exceeds $100 \%$. This can be explained by the fact that numerous respondents have indicated more than one response for this specific question.
} 
strategy of direct assessment of dimensions of fit by means of items which ask respondents to assess their subjective perception of fit.

The dependent variables are job satisfaction (JS), organizational commitment (OC), and stress and stress perception. The following measures, or scales, consist of items taken from attested scales with response options on a five-point Likert-type scale (for further details on the items, see the Appendix). The usual statistical procedures were carried out: factor and reliability analysis. At the end of the process, besides the dependent variables five variables related to P-E fit were created: P-O fit, P-J fit, P-G fit, P-V fit, P-R fit.

Dependent variables:

Job satisfaction. In this study, JS is measured via a single item aiming to measure the overall level of perceived satisfaction among our respondents. We are aware that multiple items are preferable for measuring this particular job attitude. Nevertheless, several studies have adopted such a strategy and some authors consider single item measurement to be highly reliable (Taylor 2008). Nevertheless, the fact that a single item was used to develop JS should be noted as a limitation of this study. This single item was labeled as follows: How do you estimate your current professional satisfaction? This item was measured using a 10 points Likert-type scale ( $1=$ very bad; $10=$ very good).

Organizational Commitment. There are several scales for measuring OC. Furthermore, as indicated above, OC is composed of three different dimensions (affective, normative and rational). For the purposes of this study, we used four items to develop OC previously proposed by Meyer et al. (Meyer et al. 2002) in order to measure affective commitment. These four items were measured using a five points Likert-type scale. The coefficient of reliability for this scale is .801 . A summative index was then created for regression analysis.

Stress. For the purposes of this study, we used the measure of perceived stress developed by Cohen et al. (Cohen et al. 1983). The great advantage of using such a measure is that we benefitted from a French translated version that has already been statistically validated (Bruchon-Schweitzer and Dantzer 1994). This measure is composed of fourteen items. The coefficient of reliability for this scale is .877. And a summative index was then created for regression analysis.

Independent variables:

Person-organization fit ( $P-O$ fit). In this study, we measured both goal congruence and value congruence. In this respect, we used six items, three of which were developed to understand goal congruence and three others to understand value congruence. These items were used and developed in previous research (Piasentin and Chapman 2006; Vogel and Feldman 2009). The coefficient of reliability for this scale is .917 . A summative index was then created for regression analysis.

Person-job fit (P-J fit). Three items were developed in order to gather both types of P-J fit (needssupplies and abilities-demand). These items were developed in previous research (Cable and DeRue 2002). The coefficient of reliability for this scale is .863. A summative index was then created for regression analysis.

Person-group fit ( $P-G$ fit). For this scale, two items were used to discover the congruence between respondents and their work team. Although a P-G fit measure is not widely accepted at present, we found an article in which items are proposed for measuring P-G fit (Vogel and Feldman 2009). According to this proposed measure, we used two out of the five items developed in the previously cited article. The coefficient of reliability for this scale is .820. A summative index was then created for regression analysis.

Person-vocation fit ( $P-V$ fit). Two items were used to measure this variable. These items have been developed and validated by Vogel \& Feldman (Vogel and Feldman 2009). The coefficient of reliability for this scale is .797. A summative index was then created for regression analysis. 
Person-reform fit ( $P$-R fit). As, we have not yet found a validated and tested measure of such a variable, a new measure was constructed for this study. The scale consists of five items, which have been developed in parallel structure to the other fit scales. The intent was to capture the degree of congruence between respondents with the values, goals, and objectives of the reforms in the specific health sector. The coefficient of reliability for this scale is .884. A summative index was then created for regression analysis.

Control variables. Several control variables were used in our study. Gender, age, and function (type of middle-range managers) constitute the baseline model of our analyses. These control variables were chosen to allow for comparisons with previous research, even if their respective results are somewhat mixed (Kim 2005; Van den Broeck et al. 2008).

\subsection{Statistical procedures}

Prior to assessing the reliability of our different variables, two other indicators were used for testing the condition of the dataset. The data was reviewed to ensure that the assumptions of normality were upheld. With regard to our data, all the variables used in this study fell within the suggested range (skewness should be less than 2 and kurtosis should be less than 7). Finally, the dataset was examined to determine if multicollinearity was an issue (Hayduk 1987). Indicators generally employed to assess multicollinearity are bivariate correlations (greater than .9), tolerance statistics, and VIF statistics (Carricano and Poujol 2008). The tolerance and VIF scores of our data also fell within the acceptable range for all the variables. On the basis of such evidence, we can conclude that the dataset was in good condition. Regression analyses used a set of scales that were assessed with Cronbach Alpha. Finally, summative indices, as already stated above, were created for each scale for the purposes of correlation and regression analysis.

Table 2: bivariate correlations between the study's variables

\begin{tabular}{|c|c|c|c|c|c|c|c|c|c|c|c|}
\hline & JS & $\mathbf{O C}$ & Stress & Gender & Age & $\begin{array}{l}\text { Functio } \\
\text { n }\end{array}$ & P-O fit & P-J fit & P-G fit & P-V fit & $\begin{array}{l}\text { P-REF } \\
\text { fit }\end{array}$ \\
\hline JS & 1 & & & & & & & & & & \\
\hline OC & $.361^{* * * *}$ & 1 & & & & & & & & & \\
\hline Stress & $-.507 * * *$ & $-.164 * *$ & 1 & & & & & & & & \\
\hline Gender & .004 & $.147^{* *}$ & .019 & 1 & & & & & & & \\
\hline Age & .013 & $.132 * *$ & -.060 & .048 & 1 & & & & & & \\
\hline Function & $.091^{*}$ & .028 & .008 & .016 & .001 & 1 & & & & & \\
\hline P-O fit & $.439 * * *$ & $.556^{* * * *}$ & $-.360 * * *$ & .094 & .082 & .075 & 1 & & & & \\
\hline P-J fit & $.629 * * *$ & $.384 * * *$ & $-.416^{* * *}$ & -.034 & $.136^{* *}$ & .077 & $.589^{* * * *}$ & 1 & & & \\
\hline P-G fit & $.432 * * *$ & $.291 * * *$ & $-.275^{* * * *}$ & -.017 & $.132 * *$ & $.154^{* * *}$ & $.354 * * *$ & $.518^{* * * *}$ & 1 & & \\
\hline P-V fit & $.505^{* * * *}$ & $.330 * * *$ & $-.408^{* * *}$ & -.001 & $.130^{* *}$ & .062 & $.480^{* * * *}$ & $.680^{* * *}$ & $.448^{* * * *}$ & 1 & \\
\hline P-REF fit & $.309^{* * *}$ & $.419^{* * *}$ & $-.258 * * *$ & .027 & .000 & -.039 & $.626 * * *$ & $.331 * * *$ & $.201^{* * * *}$ & $.346^{* * * *}$ & 1 \\
\hline
\end{tabular}

This study used hierarchical multiple regressions to determine the associations between P-E fit dimensions and JS, OC, and perceived stress. Every regression model included the three aforementioned control socio-demographic variables. Model 1 tests whether demographic variables add unique variance and Model 2 contributes to an understanding of the variance of our three dependent variables. In two steps, these models establish how the independent variables add any unique variance beyond that which is accounted for by the control variables. The comparison of Model 1 and Model 2 provides two important pieces of information: first, the comparison of the $\mathrm{R}^{2}$ will show which category of predictors are the most important; second, it will allow us to independently observe how the different dimensions of P-E fit contribute to the explanation of our dependent variables.

\section{Results}

Table 3 below presents the main results of hierarchical regression analyses for variables predicting job satisfaction. This shows that control variables are not associated with job satisfaction except for function, which indicates that respondents who are nursing or medical managers declare greater satisfaction than administrative, financial and technical managers. When it comes to the interpretation of the second model regarding job satisfaction, it is possible to note that P-J fit is significantly and positively related to our dependent variable as hypothesized $(\mathrm{r}=.450 ; \mathrm{p}<.001)$. To a lesser extent, $\mathrm{P}-\mathrm{G}$ fit $(\mathrm{r}=.134 ; \mathrm{p}<.01)$ and $\mathrm{P}-\mathrm{V}$ fit $(\mathrm{r}=.106 ; \mathrm{p}<.05)$ are also significantly and positively associated with 
job satisfaction. These results are in line with our research hypotheses (H1b; H1c; H1d). Furthermore, we can also point out that P-O fit and P-R fit are not related to job satisfaction in this present study. This also confirms the other hypotheses (H1a and H1e). In other words, we can safely conclude that our hypotheses concerning job satisfaction are supported by our analyses. The $\mathrm{R}^{2}$ value of the second model presented in Table 3 shows that our variables explain a substantial variation of job satisfaction (43.8\% of the job satisfaction are explained by the variables introduced in the equation). And P-E fit dimensions contribute to explaining $42.6 \%$ of the variation of job satisfaction. This indicates that P-E fit dimensions are worth taking into consideration when investigating antecedents of job satisfaction.

\section{Table 3: Hierarchical regression analyses for variables predicting job satisfaction}

\begin{tabular}{|c|c|c|c|}
\hline \multirow{4}{*}{$\begin{array}{l}\text { Step 1: Control } \\
\text { variables }\end{array}$} & & $\begin{array}{l}\text { Model 1: } \\
\text { B } \\
\text { (Std. Error) }\end{array}$ & $\begin{array}{l}\text { Model 2: } \\
\text { B } \\
\text { (Std. Error) }\end{array}$ \\
\hline & Gender & $\begin{array}{l}-.031 \\
(.224)\end{array}$ & $\begin{array}{l}-.014 \\
(.172)\end{array}$ \\
\hline & Age & $\begin{array}{l}.001 \\
(.014)\end{array}$ & $\begin{array}{l}-.095^{*} \\
(.011)\end{array}$ \\
\hline & Function & $\begin{array}{l}.102^{*} \\
(.052)\end{array}$ & $\begin{array}{l}.045 \\
(.040)\end{array}$ \\
\hline \multirow[t]{10}{*}{ Step 2: Independent variables } & P-O fit & & $\begin{array}{l}.035 \\
(.159)\end{array}$ \\
\hline & P-J fit & & $\begin{array}{l}.450 * * * \\
(168)\end{array}$ \\
\hline & P-G fit & & $\begin{array}{l}.134 * * \\
(.124)\end{array}$ \\
\hline & P-V fit & & $\begin{array}{l}.106^{*} \\
(148)\end{array}$ \\
\hline & P-R fit & & $\begin{array}{l}.077 \\
(.132)\end{array}$ \\
\hline & R2 & .011 & .438 \\
\hline & R2 change & .011 & .426 \\
\hline & F change & 1.514 & $60.340^{* * *}$ \\
\hline & Adjusted R2 & .004 & .426 \\
\hline & F statistic & .1 .514 & $38.698^{* * *} *$ \\
\hline
\end{tabular}

When it comes to the antecedents of organizational commitment, several observations can be made (see Table 4). First, gender and age (Model 1) are correlated to OC. These results suggest that male and older managers are more willing to declare commitment to their organization. Secondly, P-O fit and, to a lesser extent, P-R fit are associated with OC in this specific study (Table 4, model 2), whereas P-J fit, P-G fit, and P-V fit are not significantly related to OC. Our hypotheses $(\mathrm{H} 2 \mathrm{a}-\mathrm{H} 2 \mathrm{e})$ are supported by the data in this study. The regression models regarding OC show that $33.7 \%$ of our dependent variables' variation is explained by the independent variables, and $30.7 \%$ of this variation is explained by the P-E fit dimensions. In this case as well, P-E fit dimensions are worth studying when investigating $\mathrm{OC}$ antecedents. 
Table 4: Hierarchical regression analyses for variables predicting organizational commitment

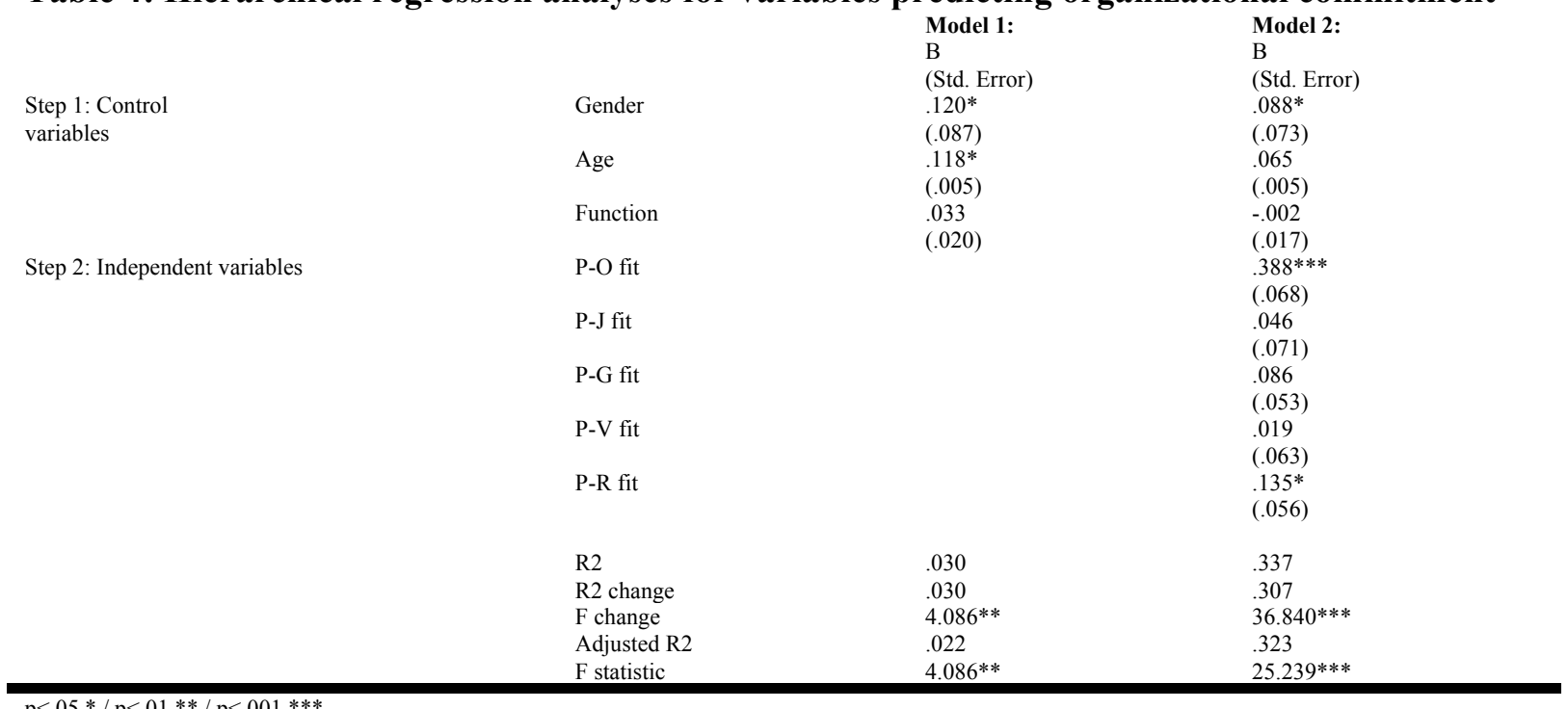

$\mathrm{p}<.05 * / \mathrm{p}<.01 * * / \mathrm{p}<.001 * * *$

With respect to perceived stress antecedents, it is also important to underline the fact that control variables are not related to this dependent variable. Furthermore, in our second model, P-J fit $(\mathrm{r}=-$ $.162 ; \mathrm{p}<.05)$ and $\mathrm{P}-\mathrm{V}$ fit $(\mathrm{r}=-.200 ; \mathrm{p}<.01)$ are negatively and significantly associated with perceived stress as expected in this study. Therefore, hypotheses $\mathrm{H} 3 \mathrm{~b}$ and $\mathrm{H} 3 \mathrm{c}$ are supported in the context of this study. On the contrary, P-O fit, P-G fit, and P-R fit are not significantly associated with perceived stress. In our theoretical analysis, we expected no significant relationship between P-O and P-R fit and perceived stress. In this regard, $\mathrm{H} 3 \mathrm{a}$ and $\mathrm{H} 3 \mathrm{e}$ are also supported. On the other hand, we expected a significant and negative correlation between P-G fit and perceived stress, which is not supported by our data. In this respect, H3d is not supported in this study.

Table 5: Hierarchical regression analyses for variables predicting stress

\begin{tabular}{|c|c|c|c|}
\hline \multirow[b]{3}{*}{$\begin{array}{l}\text { Step 1: Control } \\
\text { variables }\end{array}$} & \multirow[b]{3}{*}{ Gender } & Model 1: & $\begin{array}{l}\text { Model 2: } \\
\text { B }\end{array}$ \\
\hline & & (Std. Error) & (Std. Error) \\
\hline & & $\begin{array}{l}.031 \\
(.057)\end{array}$ & $\begin{array}{l}.034 \\
(.051)\end{array}$ \\
\hline \multirow{15}{*}{ Step 2: Independent variables } & Age & -.058 & .009 \\
\hline & & $(.003)$ & $(.003)$ \\
\hline & Function & -.001 & .037 \\
\hline & & $(.013)$ & $(.012)$ \\
\hline & P-O fit & & -.130 \\
\hline & & & $\begin{array}{l}(.047) \\
-.162 *\end{array}$ \\
\hline & P-J fit & & $\begin{array}{l}.1 .050 \\
(.050)\end{array}$ \\
\hline & P-G fit & & $\begin{array}{l}-.054 \\
(.037)\end{array}$ \\
\hline & P-V fit & & $\begin{array}{l}-.200^{* *} \\
(.044)\end{array}$ \\
\hline & P-R fit & & $\begin{array}{l}.043 \\
(.039)\end{array}$ \\
\hline & R2 & .004 & .222 \\
\hline & R2 change & .004 & .218 \\
\hline & $F$ change & .584 & $22.306 * * *$ \\
\hline & Adjusted R2 & -.003 & .207 \\
\hline & F statistic & .584 & $14.219 * * *$ \\
\hline
\end{tabular}

The table below summarizes out main observations and indicates whether our hypotheses are supported by our empirical results. 
Table 6: summary of our main observations regarding the study hypotheses

\begin{tabular}{|l|l|l|l|}
\hline & Job satisfaction & Organizational commitment & Perceived stress \\
\hline H1: P-O fit $=>$ & Supported & Supported & Supported \\
\hline H2: P-J fit => & Supported & Supported & Supported \\
\hline H3: P-G fit $=>$ & Supported & Supported & Not supported \\
\hline H4: P-V fit $=>$ & Supported & Supported & Supported \\
\hline H5: P-R fit $=>$ & Supported & Supported & Supported \\
\hline
\end{tabular}

\section{Discussion}

In this section, we will return to the main contributions of the article. Then, we will try to better explain our results in relation to previous scientific articles. Next we will discuss the usefulness of considering P-E fit as a multidimensional concept. And finally, we will demonstrate that P-R fit is a useful sub-dimension of P-E fit and is worth studying in organizational contexts that deal with profound managerial and political changes.

This article makes important contributions to three different issues:

- Antecedents of JS, OC, and perceived stress within a population of middle-range employees in a Swiss hospital dealing with political and managerial reforms.

- Analysis of the different dimensions of P-E fit in order to assess their respective impacts on three important work outcomes: JS, OC, and perceived stress.

- Development of a new P-E fit dimension called person-reforms fit (P-R fit).

As outlined in the first issue mentioned above, we have highlighted the importance of several dimensions to explain JS, OC, and stress perception in our sample. A first important assessment can be drawn from our analyses. The antecedents of JS, OC, and stress perception are not the same. According to our research, we found that different P-E fit dimensions might be considered as antecedents of our three dependent variables. For instance, P-J fit, P-V fit, and P-G fit might be considered as the most important antecedents of JS in the present study, whereas P-O fit and P-R fit are not significantly associated to JS. This first result is of great importance. In fact, if we look at the scientific literature on the subject, we can find numerous articles which consider P-O fit as an antecedent of work outcomes as if P-O fit were the main dimension (or the only dimension) of the P-E fit theoretical framework. For instance, in the public management literature, many articles use only P$\mathrm{O}$ fit as an antecedent or only as a mediator variable to better explain work outcomes such as job satisfaction (Bretz and Judge 1994) or public service motivation (Christensen and Wright 2011; Steijn 2008; Wright and Pandey 2008). However, as we demonstrate in this article, job satisfaction is more a matter of P-J, P-V, and P-G fit rather than P-O fit. This illustrates the importance of considering several rather than one single dimension of the P-E fit concept. Our current study shows that P-E fit dimensions have differentiated relationships with work outcomes. With respect to OC, our results demonstrate that $\mathrm{P}-\mathrm{O}$ fit and $\mathrm{P}-\mathrm{R}$ fit are significantly related to this specific work outcome, whereas P$\mathrm{J}, \mathrm{P}-\mathrm{V}$, and $\mathrm{P}-\mathrm{G}$ fits are not. This indicates that it is indeed useful to take into consideration different kinds of P-E fit dimensions in order to highlight the antecedents of OC. In other words, respondents who are satisfied with their job are likely to declare a better fit with their job, with the groups they belong to, the colleagues they work with, and finally with their vocation. Being comfortable in social relationships and with work tasks are important antecedents of job satisfaction. On the other hand, OC is influenced when congruence between individuals and their organization in terms of values and goals is achieved. This specific result confirms that an individual might be satisfied with his/her job without being simultaneously committed to his/her organization, and vice-versa. Furthermore, we have found that $\mathrm{OC}$ is also a matter of P-R fit, which constitutes an original piece of information developed in this study. In a context of organizational reforms and changes, individuals are more prone to declaring commitment to their organization if there is a congruence between their perception of their organization's goals and values and the ones embedded in the reforms that have taken place. In future research, it would thus be very useful to also include P-R fit in order to investigate work outcomes such as OC. In this article, we propose a reliable measurement scale regarding P-R fit. We hope this scale will be used in future research in order to confirm or counter the results we obtained in our 
investigation. Finally, it is also worth mentioning that stress perception is influenced by P-J and P-V fit. As stated earlier in this article, P-J fit relates to the complementary nature of demands or benefits of one's job position in relation to the abilities or needs of employees. In other words, if job demands are compensated by adequate job resources, then perception of stress decreases. Other recent studies have already noticed the importance of such a process (Giauque et al. 2012; Karasek and Theorell 1990; Siegrist 1996). Stress perception might also be mitigated if individuals perceive a congruence between skills and needs at the level of their occupation ( $\mathrm{P}-\mathrm{V}$ fit), whereas astonishingly, stress perception is not related to the other P-E fit dimensions such as P-O fit, P-G fit, or even P-R fit. This shows that stress perception is more specifically related to individuals' congruence with their job position and occupation rather than to their congruence with their organization, colleagues, reforms' context, or organizational changes.

The above results are very important for practitioners. They indicate that the complexity of simultaneously developing practices and tools (for instance HR practices and tools) in order to increase job satisfaction and organizational commitment. The results nevertheless suggest that different practices and tools might be developed to achieve such work outcomes. HR practices concentrated on job position and occupation (a search for compatibility between individuals' abilities and needs and the main missions and goals of their job position and occupation) could possibly consist of different HR tools such as recruitment, training, adjustment of requirements, and so on. When trying to increase compatibility between individuals' goals and values with those of their organization and those embedded in organizational reforms, HR specialists will have to develop other strategies: better communication with staff, cultural management, rewards management, and so on.

Two other important contributions regarding this paper are worth mentioning. On one hand, this paper confirms that P-E fit is a multidimensional concept, but it also shows that it does not exist as an overarching sense of fit among our respondents. As demonstrated in our study, "there is no overarching sense of fit and instead multiple dimensions of fit remain separate as predictors of the outcomes. Rather than construing multidimensional fit as a reconstruction of various dimensions of fit, this model accepts the logic in the deconstructed approach to fit and assumes that the various dimensions of fit operate separately on behavioral and psychological outcomes" (Edwards and Billsberry 2010). The results of our study are completely in line with this theoretical assumption. If an overarching sense of fit did exist among our respondents, then most of the P-E fit dimensions included in our hierarchical regression analyses would have been significantly related to our dependent variables. This is, however, not the case.

On the other hand, this study tested a new P-E fit dimension which has not been developed or included, to the best of our knowledge, in recent research on P-E fit. We have called this dimension person-reforms fit and it refers to the degree of congruence between individuals' values and the opinions and objectives, and values and missions upon which public management reforms are grounded. P-R fit is positively and significantly related to OC in this study, and factor analysis and Cronbach's analysis (reliability analysis) have shown that this new fit dimension is reliable and could be used in further research. Thus, in a context of important reforms, OC is also a matter of P-R fit.

\section{Limitations and future research}

As with all research, this study encountered several limitations. The first concerns common method bias. Resulting from the methodological strategy we used to assess "fit," which was a direct strategy aiming to measure perceived fit, this study might produce artifactual covariance principally due to consistency biases and illusory correlations. Because our respondents were asked to report predictors and outcome variables in the same online questionnaire, this survey strategy might inflate reported effect sizes (Podsakoff et al. 2003). "One approach to reducing the impact of common rater bias, which is primarily a concern in fit-attitude studies, is to temporally separate the measurement of the predictor and criterion" (Kristof-Brown et al. 2005: 293).

Another limitation worth mentioning concerns the interaction effects between fit variables. Previous studies have demonstrated that P-G fit and P-V fit may have indirect rather than direct effects on work 
outcomes (Vogel and Feldman 2009). Therefore, those latter fits may interact with other fits. These interaction effects are not investigated in the present study but it would be interesting to do so in future research. A third limitation lies in the fact that we are dealing with cross-sectional data. This study was conducted by means of an online questionnaire at one point in time. But, with regards to previous research, time might be a moderator variable when studying different kinds of fit. For instance, it is very likely that the different P-E fit dimensions included in this study might vary according, specifically, to the environmental context. As we stressed earlier, Swiss public hospitals are confronting new political and managerial pressures. Reforms are taking place and it is only a matter of time before they impact the working life of public employees. In other words, the fit dimensions we measure in this study are likely to evolve according to the development and implementation of the different processes of a reform. Caldwell, for instance, has demonstrated that at the beginning of an organizational change, P-O fit and P-J fit are decreasing among employees. He shows that after some time, the level of P-O fit quickly returns to its previous level while the level of P-J fit is more strongly and durably affected by organizational change (Caldwell 2011). Future research dealing with longitudinal data will be valuable in this specific regard. Furthermore, cross-sectional data is not very useful for finding spillover relationships between fit dimensions: "Most studies have assumed that various types of fit have additive effects (i.e., good fit on one dimension can compensate for poor fit on another). (...) Only by examining multiple types of fit longitudinally and within the same investigation can these types of spillover relationships be discerned" (Kristof-Brown et al. 2005: 323).

Finally, this study aims to discover the impact of different fit dimensions on work outcomes. Very few studies have investigated the antecedents of these fit dimensions. It is very likely that sociodemographic as well as organizational variables might greatly impact fit perceptions. Future research is required to better investigate such antecedents of different fit dimensions.

\section{Acknowledgement:}

This article is part of a broader research project financed by the Swiss National Science Foundation (project no. 13DPD6_134764/1).

\section{References:}

Agho, A. O., Mueller, C. W., \& Price, J. L. (1993). Determinants of Employee Job Satisfaction: An Empirical Test of a Causal Model. Human Relations, 46(8), 1007-1027.

Bakker, A. B., \& Demerouti, E. (2007). The Job Demands-Resources model: State of the art. Journal of Managerial Psychology, 22, 309-328.

Bakker, A. B., Van Emmerik, H., \& Van Riet, P. (2008). How job demands, resources, and burnout predict objective performance: A constructive replication. Anxiety Stress and Coping, 21(3), 309324.

Bretz, R. D., \& Judge, T. A. (1994). Person-organization fit and the theory of work adjustment: Implications for satisfaction, tenure, and career success. Journal of Vocational Behavior, 44(1), $32-54$.

Bright, L. (2007). Does Person-Organization Fit Mediate the Relationship Between Public Service Motivation and the Job Performance of Public Employees? Review of Public Personnel Administration, 27(4), 361-379, doi:10.1177/0734371X07307149.

Bright, L. (2008). Does Public Service Motivation Really Make a Difference on the Job Satisfaction and Turnover Intentions of Public Employees? The American Review of Public Administration, 38(2), 149-166.

Bruchon-Schweitzer, M., \& Dantzer, R. (1994). Introduction à la psychologie de la santé. Paris: PUF.

Büssing, A. (1992). A dynamic view of job satisfaction in psychiatric nurses in Germany. Work \& Stress, 6, 239-259.

Cable, D. M., \& DeRue, D. S. (2002). The convergent and discriminant validity of subjective fit perceptions. Journal of Applied Psychology, 87(5), 875-884.

Caldwell, S. D. (2011). Bidirectional Relationships Between Employee Fit and Organizational Change. Journal of Change Management, 11(4), 401-419, doi:10.1080/14697017.2011.590453. 
Camilleri, E. (2006). Towards Developing an Organisational Commitment - Public Service Motivation Model for the Maltese Public Service Employees. Public Policy and Administration, 21(1), 6383.

Carricano, M., \& Poujol, F. (2008). Analyse de données avec SPSS. Paris: Pearson Education.

Christensen, R. K., \& Wright, B. E. (2011). The Effects of Public Service Motivation on Job Choice Decisions: Disentangling the Contributions of Person-Organization Fit and Person-Job Fit. Journal of Public Administration Research and Theory, 21(4), 723-743, doi:10.1093/jopart/muq085.

Cohen, S., Kamarck, T., \& Mermelstein, R. (1983). A Global Measure of Perceived Stress. Journal of Health and Social Behavior, 24(4), 385-396.

Crewson, P. E. (1997). Public-Service Motivation: Building Empirical Evidence of Incidence and Effect. Journal of Public Administration Research and Theory, 7(4), 499-518.

Da Silva, N., Hutcheson, J., \& Wahl, G. D. (2010). Organizational Strategy and Employee Outcomes: A Person-Organization Fit Perspective. The Journal of Psychology, 144(2), 145-161.

Demerouti, E., Bakker, A. B., Nachreiner, F., \& Schaufeli, W. B. (2001). The Job Demands-Resources model of burnout. Journal of Applied Psychology, 51, 115-134.

Edwards, J. A., \& Billsberry, J. (2010). Testing a Multidimensional Theory of Person-Environment Fit. [Article]. Journal of Managerial Issues, 22(4), 476-493.

Eisenberger, R., Fasolo, P., \& Davis-LaMastro, V. (1990). Perceived organizational support and employee diligence, commitment, and innovation. Journal of Applied Psychology, 75, 51-59.

Evetts, J. (2009). New Professionalism and New Public Management: Changes, Continuities and Consequences. Comparative Sociology, 8, 247-266.

Giauque, D., Anderfuhren-Biget, S., \& Varone, F. (2012). Stress Perception in Public Organisations: Expanding the Job Demands-Job Resources Model by Including Public Service Motivation. Review of Public Personnel Administration, doi:10.1177/0734371x12443264.

Giauque, D., Resenterra, F., \& Siggen, M. (2010). The relationship between HRM practices and organizational commitment of knowledge workers. Facts obtained from Swiss SMEs. Human Resource Development International, 13(2), 185-205.

Gould-Williams, J., \& Davies, F. (2005). Using social exchange theory to predict the effects of HRM practice on employee outcomes. Public Management Review, 7(1), 1-24.

Hackman, J. R., \& Oldham, G. R. (1976). Motivation Through the Design of Work: Test of a Theory. Organizational behavior and human performance, 16, 250-279.

Hayduk, L. (1987). Structural equation modeling with LISREL: Essentials and advances (Vol. 13, Applied Psychological Measurement, Vol. 1). Baltimore: John Hopkins University Press.

Jae Moon, M. (2000). Organizational commitment revisited in new public management. Public Performance \& Management Review, 24(2), 177-194.

Johnson, J. V. (1986). The impact of workplace social support, job demands and work control upon cardiovascular disease in Sweden. Unpublished doctoral dissertation, Johns Hopkins University,

Johnson, J. V., \& Hall, E. (1988). Job strain, work place, social support, and cardiovascular disease. American Journal of Public Health, 78, 1336-1342.

Judge, T. A., \& Church, A. H. (2000). Job Satisfaction: Research and Practice. In C. L. Cooper, \& E. A. Locke (Eds.), Industrial and Organizational Psychology: Linking Theory with Practice (pp. 166-198). Oxford: Blackwell.

Judge, T. A., \& Klinger, R. (2007). Job Satisfaction. Subjective Well-Being at Work. In M. Eid, \& R. Larsen (Eds.), The Science of Subjective Well-Being (pp. 393-413). New York: Guilford Publications.

Karasek, R., \& Theorell, T. (1990). Healthy work: stress, productivity, and the reconstruction of working life. New York: Basic Books.

Karasek, R. A. (1979). Job demands, job latitude, and mental strain: Implicatiions for job redesign. Administrative Science Quaterly, 24, 285-308.

Kim, S. (2005). Factors Affecting State Government Information Technology Employee Turnover Intentions. The American Review of Public Administration, 35(2), 137-156, doi:10.1177/0275074004273150.

Kitchener, M. (2000). The 'Bureaucratization' of Professional Roles: The Case of Clinical Directors in UK Hospitals. Organization, 7(1), 129-154, doi:10.1177/135050840071007. 
Koch, J. L., \& Steers, R. M. (1976). Job attachment, satisfaction, and turnover among public employees. Technical Report. Oregon: Office of Naval Research, University of Oregon.

Kristof, A. L. (1996). Person-organization fit: An integrative review of its conceptualizations, measurement, and implications. Personnel Psychology, 49(1), 1-49.

Kristof-Brown, A. L., Zimmerman, R. D., \& Johnson, E. C. (2005). Consequences of Individuals' Fit at Work: A Meta-Analysis of Person-Job, Person-Organization, Person-Group, and PersonSupervisor Fit. Personnel Psychology, 58(2), 281-320.

Lallement, M., Marry, C., Loriol, M., Molinier, P., Gollac, M., Marichalar, P., et al. (2011). Maux du travail: dégradation, recomposition ou illusion? Sociologie du travail, 53, 3-36.

Larson, E. W., \& Fukami, C. W. (1984). Relationships between worker behavior and commitment to the organization and union. Paper presented at the Paper presented at the annual meeting of the Academy of Management, Boston,

Lee, J. S. Y., \& Akhtar, S. (2011). Effects of the workplace social context and job content on nurse burnout. Human Resource Management, 50(2), 227-245, doi:10.1002/hrm.20421.

Locke, E. A. (1976). The Nature and Causes of Job Satisfaction. In M. D. Dunnette (Ed.), Handbook of Industrial and Organizational Psychology (pp. 901-969). Chicago, IL: Rand McNally.

Maslach, C., Jackson, S. E., \& Leiter, M. (1996). Maslach Burnout Inventory: Manual (3rd ed.). Palo Alto, CA: Consulting Psychologists Press.

Meyer, J. P., \& Allen, N. J. (1991). A three-component conceptualization of organizational commitment. Human Resource Management Review(1), 61-89.

Meyer, J. P., \& Allen, N. J. (1997). Commitment in the Workplace: Theory, research, and application. Newbury Park, CA: Sage.

Meyer, J. P., \& Herscovitch, L. (2001). Commitment in the Workplace: Toward a general model. Human Resource Management Review(11), 299-326.

Meyer, J. P., Stanley, D. J., Herscovitch, L., \& Topolnytsky, L. (2002). Affective, continuance, and normative commitment to the organization: A meta-analysis of antecedents, correlates, and consequences. Journal of Vocational Behavior, 61, 20-52.

Meyer, J. W., \& Rowan, B. (1991). Institutionalized Organizations: Formal Structure as Myth and Ceremony. In W. Powell, \& P. DiMaggio (Eds.), The New Institutionalism in Organizational Analysis (pp. 41-62). Chicago: The University of Chicago Press.

Mowday, R. T., Porter, L. W., \& Steers, R. M. (1982). Employee-Organization Linkages: The Psychology of Commitment, Absenteeism, and Turnover. New York: Academic Press.

Muchinsky, P. M., \& Monahan, C. J. (1987). What is person-environment congruence? Supplementary versus complementary models of fit. Journal of Vocational Behavior, 31(3), 268277, doi:10.1016/0001-8791(87)90043-1.

Noblet, A., Rodwell, J., \& McWilliams, J. (2006). Organizational Change in the Public Sector: Augmenting the Demand Control Model to Predict Employee Outcomes under New Public Management. Work \& Stress, 20(4), 335-352.

Noblet, A. J., \& Rodwell, J. J. (2009). Identifying the Predictors of Employee Health and Satisfaction in an NPM Environment. Public Management Review, 11(5), 663-683.

O'Reilly, C., Chatman, J., \& Caldwell, D. F. (1991). People and organizational culture: A profile comparison approach to assessing person-organization fit. Academy of Management Journal, 34, 487-516.

Piasentin, K. A., \& Chapman, D. S. (2006). Subjective person-organization fit: Bridging the gap between conceptualization and measurement. Journal of Vocational Behavior, 69(2), 202-221, doi:10.1016/j.jvb.2006.05.001.

Podsakoff, P. M., MacKenzie, S. B., Jeong-Yeon, L., \& Podsakoff, N. P. (2003). Common Method Biases in Behavioral Research: A Critical Review of the Literature and Recommended Remedies. [Article]. Journal of Applied Psychology, 88(5), 879.

Richardsen, A. M., Burke, R. J., \& Leiter, M. P. (1992). Occupational Demands, Psychological Burnout and Anxiety among Hospital Personnel in Norway. Anxiety Stress and Coping, 5(1), 5568.

Schaufeli, W., \& Enzmann, D. (1998). The burnout companion to study and practice: A critical analysis. New York: Taylor \& Francis. 
Schaufeli, W. B., \& Bakker, A. B. (2004). Job demands, job resources, and their relationship with burnout and engagement: a multi-sample study. Journal of Organizational Behavior, 25, 293 315.

Siegrist, J. (1996). Adverse health effects of high effort low-reward conditions. Journal of Occupational Health Psychology, 1(1), 27-41.

Siegrist, J., Peter, R., Junde, A., Cremer, P., \& Siedel, D. (1990). Low status control, high effort at work and ischemic heart disease: prospective evidence from blue-collar men. Social Science \& Medicine, 31, 1127-1134.

Siegrist, J., Siegrist, K., \& Weber, I. (1986). Sociological concepts in the etiology of chronic disease: the case of ischemic heart disease. Social Science \& Medicine, 22, 247-253.

Spokane, A. R. (1985). A review of research on person-environment congruence in Holland's theory of careers. Journal of Vocational Behavior, 26, 306-343.

Staw, B. W. (1984). Organizational behavior: A review and reformulation of the field's outcome variables. Annual Review of Psychology, 35, 627-666.

Stazyk, E. C., Pandey, S. K., \& Wright, B. E. (2011). Understanding Affective Organizational Commitment: The Importance of Institutional Context. The American Review of Public Administration, 41(6), 603-624, doi:10.1177/0275074011398119.

Steijn, B. (2004). Human Resource Management and Job Satisfaction in the Dutch Public Sector. Review of Public Personnel Administration, 24(1), 291-303.

Steijn, B. (2008). Person-Environment Fit and Public Service Motivation. International Public Management Journal, 11(1), 13-27, doi:10.1080/10967490801887863.

Szilagyi, A. D., \& Wallace, M. J. (1983). Organizational behavior and performance. Glenview, IL: Scott \& Co.

Taylor, J. (2007). The impact of public service motives on work outcomes in Australia: A comparative multi-dimensional analysis. Public Administration, 85(4), 931-959.

Taylor, J. (2008). Organizational Influences, Public Service Motivation and Work Outcomes: An Australian Study. International Public Management Journal, 11(1), 67-88, doi:10.1080/10967490801887921.

Taylor, J., \& Westover, J. H. (2011). Job Satisfaction in The Public Service. Public Management Review, 13(5), 731-751, doi:10.1080/14719037.2010.532959.

Tranberg, M., Slane, S., \& Ekeberg, S. E. (1993). The relation between interest congruence and satisfaction: A meta-analysis. Journal of Vocational Behavior, 42, 253-264.

Tremblay, M., Cloutier, J., Simard, G., Chênevert, D., \& Vandenberghe, C. (2010). The role of HRM practices, procedural justice, organizational support and trust in organizational commitment and in-role and extra-role performance. The International Journal of Human Resource Management, 21(3), 405-433.

Van den Broeck, A., Vansteenkiste, M., De Witte, H., \& Lens, W. (2008). Explaining the relationships between job characteristics, burnout, and engagement: The role of basic psychological need satisfaction. Work and Stress, 22(3), 277-294.

Van Maanen, J. (1975). Police socialization: A longitudinal examination of job attitudes in an urban police department. Administration Science Quaterly, 20, 207-228.

Vézina, M. (1999). Stress et psychodynamique du travail: de nouvelles convergences. Travailler. Revue Internationale de Psychopathologie et de Psychodynamique du Travail, 1(2), 201-218.

Vogel, R. M., \& Feldman, D. C. (2009). Integrating the levels of person-environment fit: The roles of vocational fit and group fit. Journal of Vocational Behavior, 75(1), 68-81, doi:10.1016/j.jvb.2009.03.007.

Weaver, C. V. (1980). Job satisfaction in the United States in the 1970s. Journal of Applied Psychology, 65, 364-367.

Wright, B. E., \& Pandey, S. K. (2008). Public Service Motivation and the Assumption of PersonOrganization Fit. Testing the Mediating Effect of Value Congruence. Administration \& Society, $40(5), 502-521$.

Yousef, D. (2000). Organizational Commitment and Job Satisfaction as Predictors of Attitudes toward Organizational Change in a Non-Western Setting. Personnel Review, 29(5), 567-592. 
Appendix:

Items used in this research:

\begin{tabular}{|c|c|c|}
\hline $\begin{array}{l}\text { Control } \\
\text { variables: }\end{array}$ & Age: & $\begin{array}{l}\text { Female }=1 \\
\text { Male }=2 \\
\text { Five categories: } \\
0-29=1 \\
30-39=2 \\
40-49=3 \\
50-59=4 \\
60 \text { and more }=5 \\
\text { Four categories: } \\
\text { Nursing manager }=4 \\
\text { Medical manager }=3 \\
\text { Administrative/financial manager }=2 \\
\text { Technical manager }=1\end{array}$ \\
\hline $\begin{array}{l}\text { Dependent } \\
\text { variables: }\end{array}$ & $\begin{array}{r}\text { Stress } \\
\text { perception: }\end{array}$ & $\begin{array}{l}\text { 14 items coded 1-5 (never-very often) } \\
\text { 1. In the last month, how often have you been upset because of something that happened unexpectedly? } \\
\text { 2. In the last month, how often have you felt that you were unable to control the important things in your life? } \\
\text { 3. In the last month, how often have you felt nervous and "stressed"? } \\
\text { 4 In the last month, how often have you dealt successfully with irritating life hassles? (R) } \\
\text { 5. In the last month, how often have you felt that you were effectively coping with important changes that were } \\
\text { occurring in your life? (R) } \\
\text { 6.In the last month, how often have you felt confident about your ability to handle your personal problems? (R) } \\
\text { 7. In the last month, how often have you felt that things were going your way? (R) } \\
\text { 8. In the last month, how often have you found that you could not cope with all the things that you had to do? } \\
\text { 9.In the last month, how often have you been able to control irritations in your life? (R) } \\
\text { 10. In the last month, how often have you felt that you were on top of things? (R) } \\
\text { 11. In the last month, how often have you been angered because of things that happened that were outside of your } \\
\text { control? } \\
\text { 12. In the last month, how often have you found yourself thinking about things that you have to accomplish? } \\
\text { 13. In the last month, how often have you been able to control the way you spend your time? (R) } \\
\text { 14. In the last month, how often have you felt difficulties were piling up so high that you could not overcome them? }\end{array}$ \\
\hline & Job satisfaction & $\begin{array}{l}\text { Coded } 1-10(1=\text { very bad; } 10=\text { very good }) \\
\text { How do you estimate your current professional satisfaction? }\end{array}$ \\
\hline & $\begin{array}{r}\text { Organizational } \\
\text { commitment }\end{array}$ & $\begin{array}{l}\text { Coded } 1-5 \text { (strongly disagree-strongly agree) } \\
\text { 1. I really feel as if the organisation's problem's were my own } \\
\text { 2. I feel that I am emotionally attached to my organisation } \\
\text { 3. I feel a strong sense of belonging to this organisation } \\
\text { 4.There is not too much to be gained by sticking with this organization }{ }^{\circledR}\end{array}$ \\
\hline & P-G fit & $\begin{array}{l}\text { Coded 1-5 (strongly disagree-strongly agree): } \\
\text { 1. I identify strongly with the goals of my organization. } \\
\text { 2. My personal goals and the goals of my organization are very similar. } \\
\text { 3. I don't care about the goals of this organization as much as many of my co-workers do (reverse-scored). } \\
\text { 4. The things that I value in life are very similar to the things that my organization values. } \\
\text { 5. My personal values match my organization's values and culture. } \\
\text { 6. My organization's values and culture provide a good fit with the things that I value in life. } \\
\text { Coded } 1-5 \text { (strongly disagree-strongly agree): } \\
\text { 1. There is a good fit between what my job offers me and what I am looking for in a job. } \\
\text { 2. The attributes that I look for in a job are fulfilled very well by my present job. } \\
\text { 3. The match is very good between the demands of my job and my personal skills. } \\
\text { Coded } 1-5 \text { (strongly disagree-strongly agree): } \\
\text { 1. Working with the other people in my group is one of the best parts of this job. } \\
\text { 2. I get along well with the people I work with on a day-to-day basis. } \\
\text { Coded } 1-5 \text { (strongly disagree-strongly agree): } \\
\text { 1. There is a good fit between my personal interests and the kind of work I perform in my occupation (or } \\
\text { profession/trade). } \\
\text { 2. My skills and abilities are well suited for the vocation (profession/trade) that I am currently in. } \\
\text { Coded } 1-5 \text { (strongly disagree-strongly agree): } \\
\text { 1. I identify strongly with the political goals of the reforms undertaken these last years. } \\
\text { 2. I share the values and the visions on which the Swiss hospital sector reforms are grounded. } \\
\text { 3. My personal opinions and the political strategies used to reform the Swiss hospital sector are very similar. } \\
\text { 4. I think that the new principles and tools used to reorganize the Swiss hospital sector are the good ones. } \\
\text { 5. In a general way, I share the idea that reforms in the Swiss hospital sector are indispensable. }\end{array}$ \\
\hline
\end{tabular}

